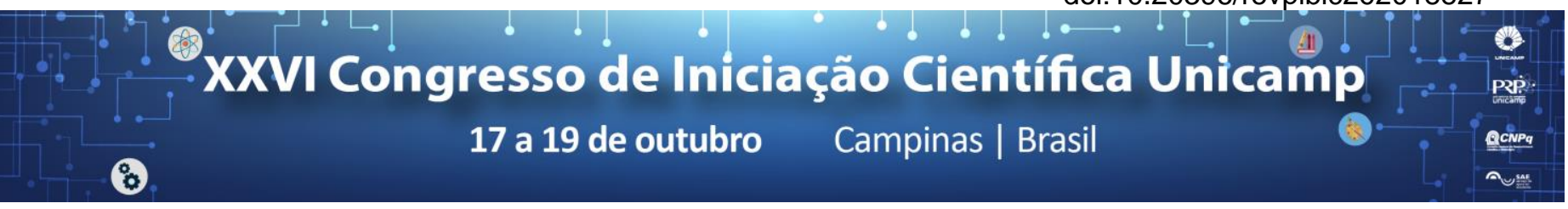

\title{
DUREZA JANKA NAS DIFERENTES DIREÇÕES ANATÔMICAS DE MADEIRAS FOLHOSAS
}

\section{Leonardo R. Deldotti*, Ingrid Z. Martins, Julio Soriano.}

\section{Resumo}

Este trabalho visou analisar a variação da dureza superficial da madeira determinada pelo método de Janka para as espécies folhosas cumaru (Dipteryx odorata), garapa (Apuleia leiocarpa) e Eucalipto Saligna ( Eucalyptus saligna) nas direções anatômicas longitudinal, tangencial e radial. Os dados de dureza obtidos de corpos de prova saturados foram analisados pelo teste de Tukey que mostrou inexistir diferenças estatíticas para as três direções anatômicas.

\section{Palavras-chave:}

Dureza superficial, direção anatomica, propriedades mecânica.

\section{Introdução}

A dureza da madeira é uma propriedade mecânica que possibilita correlações com outras propriedades, bem como a identificação do adequado processo de beneficiamento e do uso das diferentes espécies. O método de ensaio Janka é padronizado para a determinação dessa propriedade (1), que deve ser medida nas direções paralela e normal às fibras da madeira. Algumas das propriedades mecânicas são influenciadas de forma significativa pelas direções anatômicas (2), o que desperta para pesquisas aplicadas à metodologia de Janka.

O objetivo desta pesquisa foi avaliar se a dureza de Janka apresenta valores com diferenças significativas em função das direções de ortotropia da madeira.

\section{Resultados e Discussão}

Para o desenvolvimento desta pesquisa foram confeccionados nove corpos de prova de cada umas das espécies: cumaru (Dipteryx odorata), garapa (Apuleia leiocarpa) e Eucalipto Saligna (E. saligna). Os corpos de prova, na condição de madeira saturada, foram ensaiados em uma máquina universal de ensaios (EMIC DL30.000), Figura 1, recebendo uma penetração por face, totalizando duas para cada direção anatômica (longitudinal, radial e tangencial).

Figura 1. Ensaio de dureza Janka paralela às fibras (a); Detalhe da perfuração no corpo de prova (b).

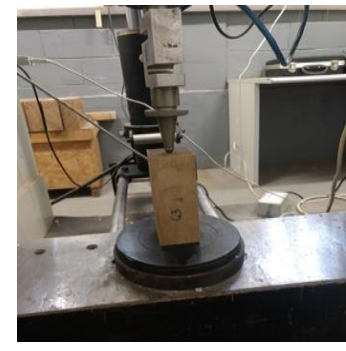

a

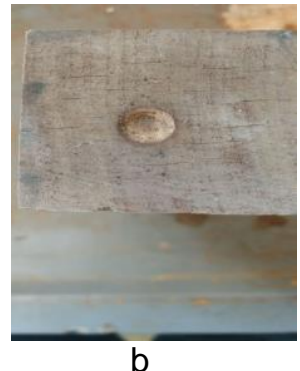

b
A análise estatística dos resultados de dureza Janka, pelo teste de assimetria e curtose atestou que os dados das três espécies estudadas estão dentro de uma distribuição normal. Também foi realizado o teste de Tukey, a 95\% de confiança (Tab. 1), que comprovou não existir diferenças estatísticas dos valores de Janka nas direções radial tangencial e longitudinal.
Tabela 1. Valor médio de dureza Janka (N).

\begin{tabular}{llccc}
\hline \multicolumn{2}{c}{ Direções } & $\mathbf{R}$ & $\mathbf{T}$ & $\mathbf{L}$ \\
\hline \multirow{4}{*}{ Garapa } & Média (N) & $7624^{(\mathrm{a})}$ & $7770^{(\mathrm{a})}$ & $7560^{(\mathrm{a})}$ \\
& D.P. (N) & 1272 & 1495 & 974 \\
& C.V. (\%) & 17 & 19 & 13 \\
\hline \multirow{2}{*}{ Eucalipto } & Média & $6625^{(\mathrm{b})}$ & $6635^{(\mathrm{b})}$ & $6511^{(\mathrm{b})}$ \\
Saligna & D.P. & 1485 & 1591 & 1088 \\
& C.V. (\%) & 22 & 24 & 17 \\
\hline \multirow{3}{*}{ Cumaru } & Média & $12361^{(\mathrm{c})}$ & $12367^{(\mathrm{c})}$ & $11807^{(\mathrm{c})}$ \\
& D.P. & 1715 & 1788 & 1455 \\
& C.V.(\%) & 14 & 14 & 12 \\
\hline
\end{tabular}

Direções: $\mathrm{R}=$ radial; $\mathrm{T}=$ tangencial; $\mathrm{L}=$ longitudinal. Nos parêntesis, letras idênticas representam valores sem diferenças estatísticas, pelo teste de Tukey.

O teste de Tukey mostrou que a dureza Janka não foi influenciada pela direção anatômica da madeira, pois os valores longitudinais e normais às fibras não apresentaram diferenças estatísticas. Esses resultados em consonância com o procedimento descrito pela norma (1), mostram a coerência em não se distinguir os valores em relação direções anatômicas radial e tangencial.

\section{Conclusões}

A pesquisa mostrou para as três espécies folhosas em condição de madeira saturada que a dureza Janka não apresenta diferenças estatísticas para as direções radial, tangencial e longitudinal.

\section{Agradecimentos}

Ao apoio financeiro desta pesquisa de iniciação científica pelo CNPq e ao apoio técnico do LabEND-FEAGRI.

\footnotetext{
${ }^{1}$ ASSOCIAÇÃO BRASILEIRA DE NORMAS TÉCNICAS -ABNT. NBR 7190: Projeto de estruturas de madeira. Rio de Janeiro, ABNT, 1997.
}

${ }^{2}$ CALIL Jr., C.; LAHR, F.A.R.; DIAS, A.A. Dimensionamento de elementos estruturais de madeira. 1ed. Barueri: Editora Manole, 2003. 